\title{
Experimental Investigations of Composite Leaf Spring
}

\author{
P. D. Wadile, K. A. Mahajan \\ (Department of Mechanical Engineering, M.E.S. College of Engineering, S. P. Pune University, India)
}

\begin{abstract}
Leaf spring is an important aspect in automobile industries. Leaf spring has tendency to absorb the vibration and sudden impact when vehicle is in running condition on irregular road surface. leaf spring plays active role in suspension system for reducing the vibration and improving the comfort ride to the passenger. Traditional steel leaf spring was bulky hence in recent scenario conventional leaf spring is replace with composite leaf spring. In this work steel mono leaf spring replaced by composite material which is EGlass/Epoxy. Experimental reading has been taken in LABVIEW Hardware and software in the form of strain gauge measurement method. In experimental result it is found that the stress $480.7 \mathrm{MPa}$ for maximum $4000 \mathrm{~N}$ loading conditionis less than steel leaf spring. The deflection has been found out for $4000 \mathrm{~N}$ load is $43 \mathrm{~mm}$. After studying the result of stress and deflection of composite leaf spring, shows that composite leaf spring is the alternate option to replace steel leaf spring.
\end{abstract}

Keywords - Composite leaf springs, NI Lab view software, Composite leaf springs and stiffness.

\section{INTRODUCTION}

Leaf Springs and coil springs are acting as suspension element on light weight duty vehicles which is necessary for avoiding bumping effects and sudden impact due to surface irregularities of road. To avoid bumping impact and vertical vibration of the system springs are used and also to improve the comfort ride[1-4]. The main function of leaf spring is absorb the shock and take care of crucial parts of the vehicle those are highly affected due to vertical vibration and bumping impact. Nowadays weight reduction of the spring is the most important design parameter by maintaining the spring stiffness. The conventional leaf spring had almost $10-20 \%$ of un-sprung weight. Due to this vibration occurs and the comfort level provided by the spring is reduced[5-7]. The main objectives of the leaf spring are to resist the vibration, to protect the vehicle body from damage and to provide smooth ride.

\section{MATERIAL SELECTION}

Composite materials and composite structural element whose mechanical properties are controlled for high strength and stiffness. Continuous fiber is embedded in a polymeric matrix. For high strength to weight ratio composite material are used.There are different types of material are available such as Carbon /Graphite fiber, E-Glass/Epoxy, S2-Glass epoxy etc. Fiber-reinforced polymers are normally developed for weight optimization criteria because of weight reduction consideration and improvement of strength[8]. The selection of fiber depends on physical, mechanical and thermal properties. The mechanical properties required are elastic modulus and strength and some thermal properties required are thermal expansion and thermal conductivity. Resign used for composite composition is known as matrix and fibres are generally bound in matrix polymer. The matrix polymer strength is always lower than fiber. The function of matrix is to transfer the load from one fiber to adjacent fiber. Thermoset and thermoplastic are main two types of polymer matrix. The most probably used polymer is thermoset. It contains epoxy material which is a resin.

In leaf springs the energy is stored as elastic strain energy. Further since a portion of the spring's mass is associated with vertical motion of the wheel, it is desirable to reduce its mass as well as other contributing unsprung mass to maximize vehicle control. For the selection of spring configuration and construction, material should be selected on the basis of strain energy. The amount of strain energy that can be stored in the spring can be expressed as[9]

$$
S=\frac{1}{2} \frac{\sigma}{\rho E}
$$

Where $\sigma$ is maximum allowable stress induced in longitudinal direction, $\mathrm{E}$ is modulus of elasticity in longitudinal direction and $\rho$ is density of the spring material. From stored energy equation it is clear that for the maximum strain energy required low modulus of elasticity.. The main application of composite material widely used in aerospace. In aerospace application high stiffness to weight ratios is necessary. Due to maintain stiffness 
to weight ratio composite material widely accepted in automobile industries. The properties of composite material are high strength, high solidity, and great fatigue factor properties.

In the present work, a steel mono leaf spring is replaced by composite leaf spring. The main objectives of this paper are to study experimentally behavior of stresses and deflection for different loading condition for composite mono leaf spring.

\section{COMPOSITE LEAF SPRING}

In the experimental study of composite leaf spring Maruti Omini leaf spring have been selected for the comparison with composite leaf spring. From the literatur survey it has been observed that Eglass/Epoxy composite can be use and the specification and material properties of composite leaf spring are given in table 1 and table 2 .

Table 1 Parameter and value

\begin{tabular}{|l|l|}
\hline Parameters & Value \\
\hline Total length & $1125 \mathrm{~mm}$ \\
\hline Thickness & $20-8 \mathrm{~mm}$ \\
\hline Width & $30-50 \mathrm{~mm}$ \\
\hline Camber & $125 \mathrm{~mm}$ \\
\hline Force on spring & $50 \mathrm{~N}$ to $3000 \mathrm{~N}$ \\
\hline
\end{tabular}

Table 2 Material Properties and values [10]

\begin{tabular}{|l|l|l|}
\hline Sr. No. & Properties & Value \\
\hline 1 & Tensile modulus along X-direction(Ex),MPa & 34000 \\
\hline 2 & Tensile modulus along Y-direction(Ey),MPa & 6530 \\
\hline 3 & Tensile modulus along Z-direction(Ez),MPa & 6530 \\
\hline 4 & Tensile strength of the material, MPa & 900 \\
\hline 5 & Compressive strength of the material, MPa & 450 \\
\hline 6 & Shear modulus along XY-direction(Gxy), MPa & 2433 \\
\hline 7 & Shear modulus along YZ-direction(Gyz), MPa & 1698 \\
\hline 8 & Shear modulus along ZX-direction(Gzx), MPa & 2433 \\
\hline 9 & Poisson ratio along XY-direction (NUxy) & 0.217 \\
\hline 10 & Poisson ratio along YZ-direction (NUyz) & 0.366 \\
\hline 11 & Poisson ratio along ZX-direction (NUzx) & 0.217 \\
\hline 12 & Density of the material ( $\boldsymbol{P}$ ), kg/mm3 & $2.6 \mathrm{E}-06$ \\
\hline 13 & Flexure modulus of the material, MPa & 40000 \\
\hline 14 & Flexure strength of the material, MPa & 1200 \\
\hline
\end{tabular}

\section{EXPERIMENTAL SET UP}

For the experimental setup, the main requirement is to fix the leaf spring on the testing machine so fixture is made for supporting the leaf spring. The measurement of strain and deflection is done by using strain gauge and data is captured by NI LAB VIEW. Leaf spring is fixed on one side as per according to vehicle condition on the UTM. The leaf spring requires a fixture to fix the leaf spring on UTM from one end and another end is free to displace along longitudinal direction. The fixture is made of MS plate with $20 \mathrm{~mm}$ thickness for sustain the require load on spring as shown in Fig.1. The function of this fixture is to hold a leaf spring on one end and another end movement is fixed. The specification of fixture is given in Table 3.

Table 3 Specification of designed fixture

\begin{tabular}{|l|l|l|}
\hline Sr. No. & Parameter & dimension \\
\hline 1 & MS Plate 1 & $30 \times 16.5 \times 2 \mathrm{~cm}$ \\
\hline 2 & MS Plate 2 & $35 \times 16.5 \times 2 \mathrm{~cm}$ \\
\hline
\end{tabular}




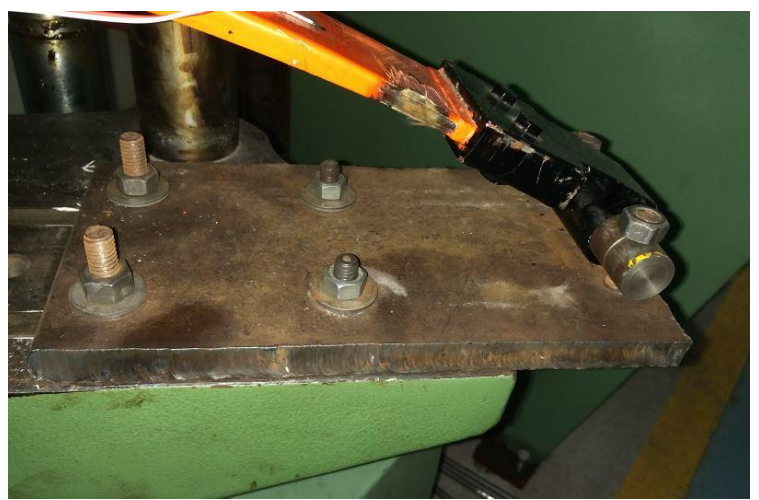

\subsection{Strain gauges:}

Fig 1 Fixture arrangement on UTM with fix end.

Strain gauges are used for measuring the stress in the form of strain. In the testing, compessive load is applied on leaf spring that causes deflection and this deflection producing stress in the spring. This stress is calculated from the strain. The strain gauges used for strain measurement is of bonded type. The strain gauge used in leaf spring testing is of $350 \Omega$ and gauge factor for strain gauge used is 2.05. Adhesive is used for strain gauge installation on the leaf spring.

\subsection{Strain gauge measurement:}

Generally for strain gauge measurement Wheatstone bride circuit is used. In this work for the measurement of the strain Quarter bridge circuit is used and the circuit diagram of Quarter Bridge is shown in Fig 2.

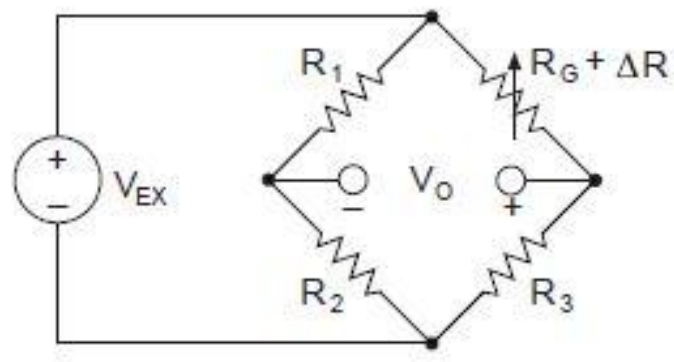

Fig 2 Quarter bridge circuit

\subsection{Strain Gauge Locations:}

The location of strain gauge has been evaluated from the FEA for stress and from the results maximum stress intensity locations were marked. The strain gauges were pasted on that respective loaction of leaf spring. Two strain gauges are used for measuring the strain and their distance from fix end as shown in table 4 .

Table 4 Strain gauge location on leaf spring

\begin{tabular}{|l|l|l|}
\hline $\begin{array}{l}\text { First Strain gauge location from fixed } \\
\text { eye }\end{array}$ & L1 & $290 \mathrm{~mm}$ \\
\hline $\begin{array}{l}\text { Second Strain gauge location from } \\
\text { fixed eye }\end{array}$ & L2 & $850 \mathrm{~mm}$ \\
\hline
\end{tabular}

\subsection{Data Acquisition Hardware:}

NI lab hardware and software are used for measuring strain. Data acquision hardware and software consist of cDAQ 9174 four slot chassis and universal NI 9219 for strain measurement module.

\subsection{Experimental Procedure:}

The fixture has been clamped on the UTM work table using bolts. One end othe leaf spring clamped in the fixture and another end kept free as shown in Fig. 3. Strain gauges were connected to the wire and other end other wire is connected to data acquisition hardware. Copmressive load applied gradually at the centre of the leaf spring. The load applied from $580 \mathrm{~N}$ to $4000 \mathrm{~N}$ and delection as well as strain measured using NI LabView as shown in Fig.4-7. 


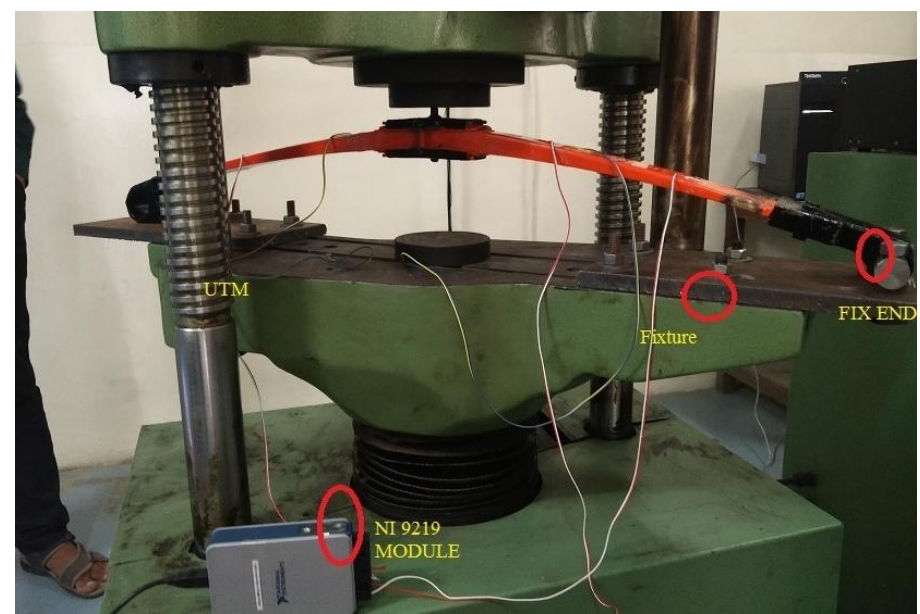

Fig 3 Experimental setup

\subsection{Experimental observation:}

Experimental results are taken for 580 to $4000 \mathrm{~N}$.

\section{For $580 \mathrm{~N}$ load}

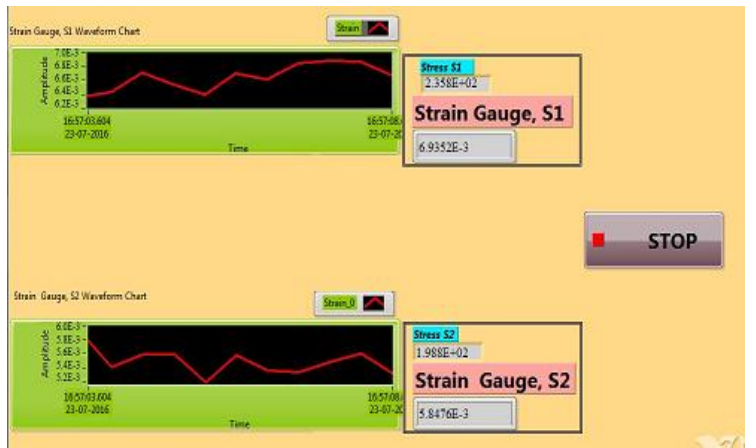

Fig. 4 Strain and strain measurement for $580 \mathrm{~N}$ load

For $1000 \mathrm{~N}$ load

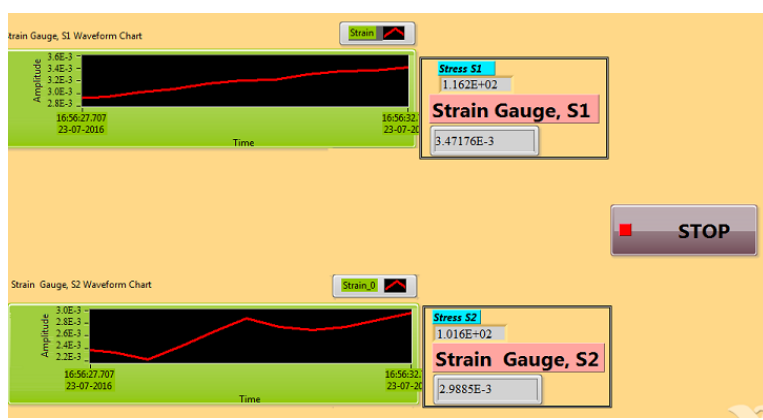

Fig. 6 Strain and strain measurement for $1000 \mathrm{~N}$ load
For $780 \mathrm{~N}$ load

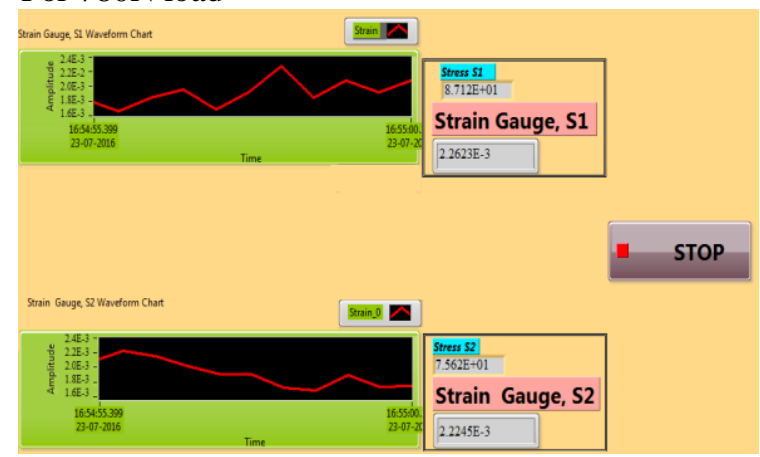

Fig. 5 Strain and strain measurement for $780 \mathrm{~N}$ load

For $2000 \mathrm{~N}$ load

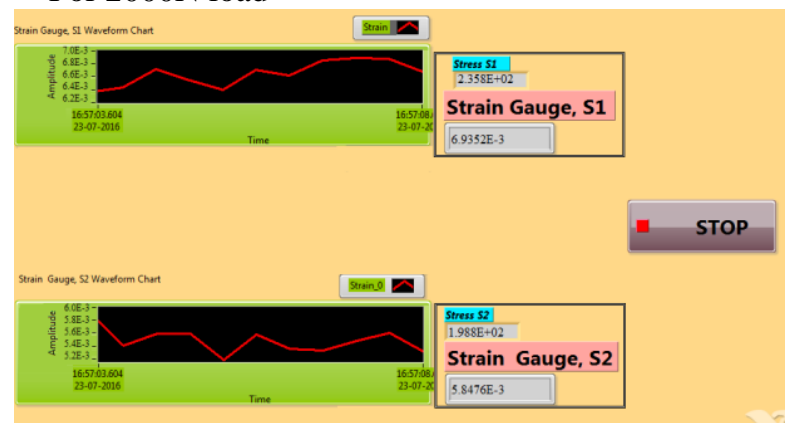

Fig .7 Strain and strain measurement for 2000N load

Following are the readings for Leaf Spring of E-Glass/Epoxy material. The readings have been taken on Universal Testing Machine with the help of NI Lab View hardware and software. Experimental reading of strain is given in Table 5 and calculated stress reading is given in Table 6.

Table 5 Experimental strain reading for composite leaf spring.

\begin{tabular}{|l|l|l|l|l|}
\hline \multirow{2}{*}{ Sr. No. } & $\begin{array}{l}\text { Load } \\
(\mathrm{N})\end{array}$ & \multirow{2}{*}{$\begin{array}{l}\text { Deflection } \\
(\mathrm{mm})\end{array}$} & 6.3 & \multicolumn{2}{|l|}{ Strain Meter Reading } \\
\cline { 3 - 5 } & 580 & 9.6 & $1.908 \mathrm{E}-3$ & L2 \\
\hline 2 & 780 & 12 & $2.2623 \mathrm{E}-3$ & $1.6789 \mathrm{E}-3$ \\
\hline 3 & 880 & 14.8 & $2.92643 \mathrm{E}-3$ & $2.2245 \mathrm{E}-3$ \\
\hline 4 & 1000 & 26 & $3.47176 \mathrm{E}-3$ & $2.52 \mathrm{E}-3$ \\
\hline 5 & 2000 & 34 & $6.9352 \mathrm{E}-3$ & $2.9885 \mathrm{E}-3$ \\
\hline 6 & 3000 & 43 & $1.053 \mathrm{E}-2$ & $5.8476 \mathrm{E}-3$ \\
\hline 7 & 4000 & & $1.4139 \mathrm{E}-2$ & $8.1711 \mathrm{E}-3$ \\
\hline
\end{tabular}


Table 6 Experimental calculated stress for composite leaf spring.

\begin{tabular}{|l|l|l|l|l|}
\hline \multirow{2}{*}{ Sr. No. } & \multirow{2}{*}{$\begin{array}{l}\text { Load } \\
\text { (N) }\end{array}$} & \multirow{2}{*}{$\begin{array}{l}\text { Deflection } \\
(\mathrm{mm})\end{array}$} & 6.3 & Calculated Stress \\
\cline { 4 - 5 } & 580 & 9.6 & 64.9 & L2 \\
\hline 1 & 780 & 12 & 87.12 & 56.78 \\
\hline 3 & 880 & 14.8 & 99.95 & 75.62 \\
\hline 4 & 1000 & 26 & 116.2 & 85.71 \\
\hline 5 & 2000 & 34 & 235.8 & 101.6 \\
\hline 6 & 3000 & 43 & 357.32 & 198.82 \\
\hline 7 & 4000 & 480.7 & 277.82 \\
\hline
\end{tabular}

\section{RESULTS AND DISCUSSION}

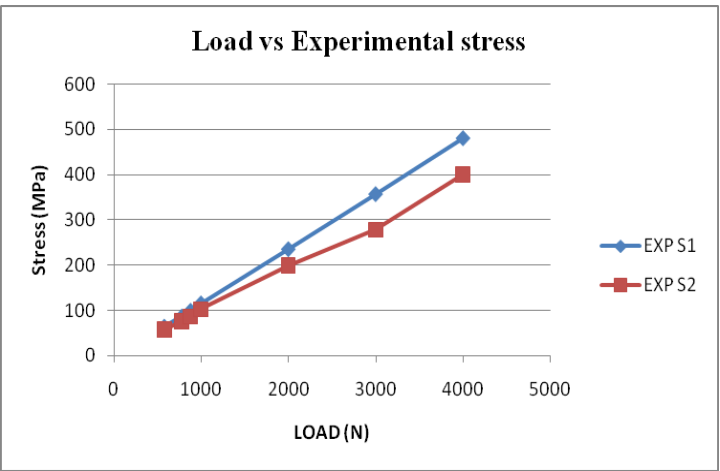

Fig 8 Load vs Experimental stress

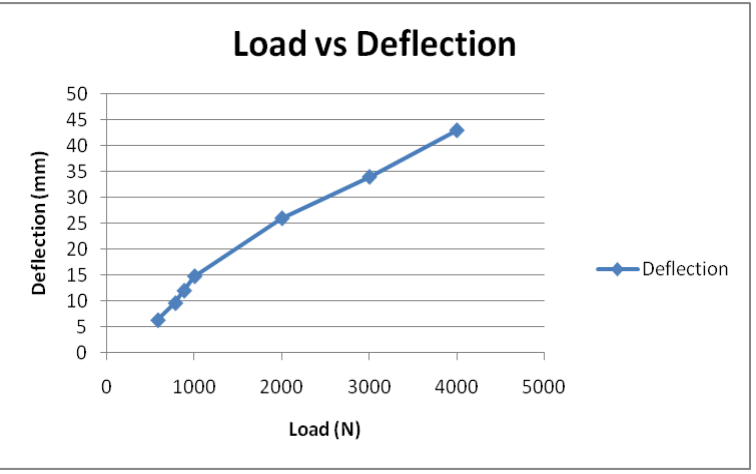

Fig 9 Load vs Experimental Deflection

It is observed that in Fig. 8 as the load increases the experimental stresses also increases but the experimental stress S2 on location L2 has less stress as compared to experimental stress S1 on location L1. Because experimental stress S1 is located near to fix end of composite leaf spring hence the stresses occurs in the leaf spring induced maximum at the fixed end where as the stresses at free end is less.It is observed that in Fig 9. as the load increases the deflection of composite leaf spring occurs. Deflection of spring is depending on stiffness properties of the leaf spring. The deflection of spring versus load shows the linear behaviour of composite leaf spring.Experimental results of composite leaf spring are compared with numerical result it is found that the stresses acting in spring are much less as compare to steel leaf spring. Experimental max stress occurs at $4000 \mathrm{~N}$ for location 1 and for location 2 are $480.7 \mathrm{MPa}$ and $400.23 \mathrm{MPa}$ and deflection occurs for that load is $43 \mathrm{~mm}$.

\section{CONCLUSIONS}

Eglass/Epoxy composite leaf spring was tested and it is found that the stresses at L1 location is maximum as compare to stresses at the location L2. The maximum stress occurs is $480.7 \mathrm{MPa}$ for the $4000 \mathrm{~N}$ loading condition which is less than allowable stress. The maximum deflection for $4000 \mathrm{~N}$ load is $43 \mathrm{~mm}$ which is also permissible in range. In Experimentation it is observed that the stresses and deflection are linearly increases with increase in load. After studying all this parameter conclude that E-glass/Epoxy composite leaf spring is the best option for replacement of composite leaf spring.

\section{REFERENCES}

[1] M. Sureshkumar, et al ,Design, fabrication and analysis of hybrid fiber composite mono leaf spring using carbon and E-glass fiber for automotive suspension application, Russian translation published in Mekhanika Kompozitnykh Material,50(1),2014,159-168.

[2] G. Siddaramanna, Shiva Shankar, Mono composite leaf spring for light weight vehicle-Design, End joint analysis and testing,material science,12(3), 2006.

[3] K. K. Jadhav, et al ,Experimentation Investigation and Numerical analysis of composite leaf spring, International journals of engineering science and technology,3(6), 2016. 
[4] Mahamood M. Shokriech, et al ,Analysis and optimization of composite leaf spring, composite structures,2003,317325.

[5] Pankaj Saini, et al ,Design and analysis of composite leaf spring for light vehicles, International journal of Innovative research in science, Engineering and technology,2,2013.

[6] M. P. Palaskar, Optimization of mono leaf spring by parabolic variation of thickness along the length, International journals of scientific and research publication,4(5), 2014.

[7] P. P. Patil, Critical review of research paper for analysis of multi leaf spring,International journals for latest trends in engineering and technology,3(5),2014.

[8] R. K. Rathore, et al ,Weight optimization of mono parabolic leaf spring," International journals of engineering research and technology,3(7), 2014.

[9] Issac M. Daniel, Engineering Mechanics of composite materials( south Asia second edition).

[10] Joo-tech Jeffrey KUEH, Finite element analysis on the static and fatigue characteristics of composite multi leaf spring,Journal of Zhejiang University applied physics and engineering,2012, 159-164. 